\title{
FITOSSANIDADE
}

\section{INFLUENNCIA DE TRICOMAS DO ALGODOEIRO SOBRE OS ASPECTOS BIOLÓGICOS E CAPACIDADE PREDATÓRIA DE CHRYSOPERLA EXTERNA (HAGEN) ALIMENTADA COM APHIS GOSSYPII GLOVER ${ }^{(1)}$}

\author{
TEREZINHA MONTEIRO DOS SANTOS ${ }^{(2)}$; ARLINDO LEAL BOIÇA JÚNIOR ${ }^{(2)}$; \\ JOSÉ JANDUÍ SOARES ${ }^{(3)}$
}

\begin{abstract}
RESUMO
Os tricomas do algodoeiro atuam como um dos fatores de resistência a Aphis gossypii Glover, e podem afetar também seus inimigos naturais, reduzindo a eficiência desses agentes de controle e aumentando o tempo de procura pela presa. Neste trabalho, em condições de laboratório, avaliou-se a influência da densidade de tricomas das cultivares de algodoeiro Antares (pouco pilosa), CNPA 7H (hirsuta) e Deltapine Acala 90 (pilosa) sobre os aspectos biológicos e a capacidade predatória de Chrysoperla externa (Hagen) alimentada com A. gossypii criado em plântulas da cultivar de algodoeiro IAC 22. Verificou-se que a duração e a viabilidade das fases de desenvolvimento de C. externa não foram influenciadas pelos tricomas das cultivares. O período de oviposição de C. externa foi maior quando suas larvas se alimentaram de A. gossypii sobre folhas da cultivar Antares. A capacidade diária e a total de oviposição de C. externa não sofreram influência das cultivares de algodoeiro nas quais essa espécie foi mantida durante a fase larval. Fêmeas de C. externa, alimentadas durante a fase larval com A. gossypii e mantidas sobre folhas da cultivar Antares, apresentaram maior longevidade. Durante o período larval, C. externa consumiu respectivamente, 544,0; 494,3 e 454,8 pulgões, quando mantida sobre folhas das cultivares CNPA $7 \mathrm{H}$, Antares e Deltapine Acala 90. As cultivares de algodoeiro demonstraram compatibilidade com esse predador, o que indica a possibilidade de integração de cultivares resistentes com diferentes níveis de densidade de tricomas com C. externa para controle do pulgão A. gossypii.
\end{abstract}

Palavras-chave: resistência de plantas, pulgão, interação tritrófica, predador.

\section{ABSTRACT \\ INFLUENCE OF COTTON TRICHOMES ON BIOLOGICAL ASPECTS AND PREDATORY ABILITY OF CHRYSOPERLA EXTERNA (HAGEN) FED WITH APHIS GOSSYPII GLOVER}

Cotton trichomes, acting as a resistance factor to Aphis gossypii Glover, can also affect its natural enemies, reducing the efficacy of the control agents and increasing prey searching time. The effects of different trichome densities, observed in three cotton cultivars (Antares - low pilosity; CNPA 7H - hirsute and Deltapine Acala 90 - high pilose), on biological aspects and predatory ability of Chrysoperla externa (Hagen), fed on A. gossypii reared on IAC-22 cotton seedlings, were evaluated. Developmental period and viability of $C$. externa larva were not significantly affected by trichome densities. However, $C$. externa

$\left({ }^{1}\right)$ Recebido para publicação em 4 de novembro de 2002 e aceito em 24 de junho de 2003.

$\left(^{2}\right)$ Departamento de Fitossanidade, UNESP/FCAV, Via de Acesso Prof. Paulo Donato Castellane, s/n, $14884-900$ Jaboticabal (SP). E-mail: tmonteirosantos@ig.com.br ; aboicajr@fcav.unesp.br

$\left({ }^{3}\right)$ EMBRAPA- CNPA, Rua Osvaldo Cruz, 1.143, 58107-720 Campina Grande (PB). 
oviposition period was longer when larva were fed on A. gossypii reared on Antares leaves. Also, daily and total egg numbers laid by C. externa were not influenced by any cotton cultivars on which it was maintained during the larval phase. Highest longevity of $C$. externa females was observed when they were fed, during the larval phase, on leaves of the lowest pilosity cultivar (Antares). During larval period, C. externa consumed, respectively, 540.0; 494.3 and 454.8 aphids, when it was maintained on CNPA 7H, Antares and Detapine Acala 90 cultivars leaves. Cotton cultivars showed good compatibilities with the predator species; the results clearly indicate the feasibility of $A$. gossypii aphid control through the use of C. externa on cotton cultivars with proper trichome densities.

Key words: host-plant resistance, tritrophic interaction, predator, aphid.

\section{INTRODUÇÃO}

Dentre os pulgões que infestam a cultura do algodoeiro, Aphis gossypii Glover, 1877 é o mais comum e prejudicial, ocorrendo logo após a germinação e permanecendo até o fim do ciclo da cultura (ARANTES et al., 1998). Esses pulgões têm preferência por tecidos tenros da planta, da face inferior das folhas (MAtTews, 1989). Além de inocularem viroses, produzem uma secreção adocicada, pegajosa e brilhante, o honeydew, que atrai formigas e contribui para o desenvolvimento de fungos do gênero Capnodium, conhecidos como fumagina, que prejudicam a respiração e fotossíntese das folhas (NAVEED et al., 1995; CARVAlho, 1996; SAntos, 1999). Quando ocorrem na fase final da cultura, depreciam a qualidade da fibra pela produção excessiva de honeydew, afetando sua utilização industrial (KABISSA et al., 1996; ARANTES et al., 1998; SAntos, 1999). Os maiores surtos populacionais de $A$. gossypii estão relacionados às aplicações de inseticidas para controle de pragas, eliminando a maioria dos seus inimigos naturais (HARRIs et al., 1994). Técnicas alternativas ao controle químico do pulgão do algodoeiro têm sido pesquisadas como a resistência de plantas e o controle biológico (Harris et al., 1994; WeAtHERSBEE et al., 1995; KABISSA et al., 1996).

Através de resultados experimentais, sabe-se que a pilosidade do algodoeiro afeta o pulgão $A$. gossypii. WeATHERSBEe et al. (1995) constataram que o mecanismo de resistência a esse hemíptero está associado com a ausência de tricomas. WeAthersbeE e HARDEE (1994) demonstraram que sua população aumenta linearmente com a densidade de tricomas nas folhas do algodoeiro. NAVEED et al. (1995) reportaram que cultivares de algodoeiro com menor número e tamanho de tricomas apresentam maior população de A. gossypii.

O conhecimento da resposta do inimigo natural às características de resistência da planta é importante para o sucesso na integração controle biológico e cultivares resistentes a insetos em programas de manejo integrado de pragas (BARBOUR et al., 1997). Os tricomas influenciam o comportamento e habilidade do inimigo natural (HARE, 1992), reduzindo a eficiência de parasitóides e predadores e aumentando o tempo de procura pela presa (Botrell et al., 1998).
A taxa de predação de larvas de Chrysoperla rufilabris (Burmeister) sobre ovos de Helicoverpa zea (Boddie) em algodoeiro foi maior em cultivares glabras em relação às pilosas, evidenciando que os tricomas atuam como barreiras mecânicas, reduzindo a mobilidade e, conseqüentemente, a capacidade predatória desse crisopídeo (TREACY et al., 1987). Em tomateiro, Heinz e Zalom (1996) verificaram que adultos do coccinelídeo Delphastus pusillus Le Conte foram mais rápidos nos seus deslocamentos em cultivares glabras em comparação com uma pilosa.

Segundo Mohite e Uthamasamy (1998), há uma associação negativa entre a densidade dos tricomas e a taxa de predação de ovos de H. zea por Chrysoperla carnea (Stephens). Em outras pesquisas, no entanto, os tricomas não exercem influência sobre os inimigos naturais. POWELl e LAMBERT (1993) observaram que o predador Geocoris punctipes (Say) manteve níveis similares de predação sobre ovos de $H$. zea em cultivares de soja pilosa, moderadamente pilosa e glabra. Heinz e PARrella (1994) ressaltaram que a longevidade de D. pusillus e quatro espécies pertencentes ao gênero Encarsia não variou entre as cultivares de poinsétia com diferentes densidades de tricomas. MAEDA (2002) observou que, em casa de vegetação, os tricomas de diferentes cultivares de algodoeiro não influenciaram a taxa de predação de ovos de Alabama argillacea (Hübner) por larvas de Chrysoperla externa (Hagen). Considerando que, entre os inimigos naturais do pulgão-do-algodoeiro, os crisopídeos são alguns dos mais eficientes predadores, o objetivo do presente trabalho foi avaliar os aspectos biológicos de C. externa alimentada com $A$. gossypii sobre folhas de cultivares de algodoeiro de características pouco pilosa, hirsuta (média pilosidade) e pilosa.

\section{MATERIAL E MÉTODOS}

A pesquisa foi desenvolvida no Laboratório de Resistência de Plantas a Insetos, do Departamento de Fitossanidade, UNESP/Faculdade de Ciências Agrárias e Veterinárias, Campus de Jaboticabal (SP). Os insetos foram mantidos em câmara climatizada a 25 $\pm 1^{\circ} \mathrm{C}$, UR de $70 \pm 5 \%$ e fotofase de 12 horas. 


\subsection{Criação de A.gossypii e C.externa}

Os pulgões foram coletados em folhas de algodoeiro e transferidos para plantas da cultivar IAC 22, semeada em copos descartáveis com capacidade de $500 \mathrm{~mL}$, contendo terra como substrato. Semanalmente, novas plantas foram infestadas com pulgões, visando obter elevadas populações de $A$. gossypii para o desenvolvimento dos experimentos. A criação foi mantida em estufas de armação de metal de $3,0 \mathrm{~m}$ de largura por 2,0 m de altura e 2,0 m de comprimento, revestidas por tela antiafídeo, evitando a infestação de outras espécies de pulgões e inimigos naturais. Exemplares dos pulgões foram enviados para identificação ao Dr. Carlos Roberto de Souza, da Universidade Federal de São Carlos.

Adultos de C. externa foram coletados em cultura de algodão e transferidos para o laboratório. Foram mantidos 20 casais do predador por gaiola cilíndrica de PVC de $20 \mathrm{~cm}$ de altura x $20 \mathrm{~cm}$ de diâmetro. Sua extremidade inferior foi apoiada em bandeja circular de PVC de $24 \mathrm{~cm}$ de diâmetro, forrada com papel-toalha branco, enquanto a extremidade superior foi vedada com filme de polietileno. Internamente, a gaiola foi revestida com papel-filtro para a oviposição. $\mathrm{O}$ alimento consistiu de dieta à base de levedo de cerveja e mel em partes iguais, de consistência pastosa, pincelada em tiras de parafilm ${ }^{\circledR}$ e fixada na parede interna da gaiola. Foi também fornecida água destilada por meio de algodão acondicionado em frasco de $10 \mathrm{~mL}$. Diariamente, o papel contendo os ovos foi substituído; os pedicelos dos ovos foram cortados com auxílio de uma tesoura. Os ovos de C. externa foram individualizados em tubos de vidro de $2,5 \mathrm{~cm}$ de diâmetro $\times 8,5 \mathrm{~cm}$ de altura, vedados com filme de polietileno. As larvas recém-eclodidas foram alimentadas até a fase de pupa com pulgões $A$. gossypii obtidos da criação massal.

\subsection{Aspectos biológicos de C. externa}

Utilizaram-se as cultivares de algodoeiro Deltapine Acala 90 (pilosa), CNPA 7H (hirsuta) e Antares (pouco pilosa), apresentando, respectivamente $145,2 \pm 15,3 ; 32,4 \pm 3,2$ e $14,8 \pm 3,5$ tricomas por $\mathrm{cm}^{2}$ de folha. Discos de $5 \mathrm{~cm}$ de diâmetro foram cortados do centro das folhas das cultivares de algodoeiro, conforme TREACY et al. (1987). Um disco foliar de cada cultivar foi mantido em placa de Petri de $12 \mathrm{~cm}$ de diâmetro, contendo uma camada de $1,0 \mathrm{~cm}$ de ágar a $1 \%$, com a superfície abaxial voltada para cima, pois, de acordo com Treacy et al. (1987), a densidade de tricomas é maior na superfície inferior das folhas do algodoeiro. Sobre cada disco foram transferidas ninfas de terceiro e quarto ínstares do pulgão $A$. gossypii e uma larva de C. externa recém-eclodida. Diariamente, os pulgões foram oferecidos ad libitum e, os discos foliares e o substrato à base de ágar, trocados a cada três dias. Avaliaram-se os seguintes parâmetros: número, duração e viabilidade de cada ínstar; massa 24 horas após cada ecdise; duração e viabilidade das fases de larva, pré-pupa, pupa e larva-adulto. Utilizou-se o delineamento inteiramente casualizado e os tratamentos foram constituídos pelos discos de folhas das cultivares de algodoeiro, em 30 repetições cada um. Os dados foram submetidos à análise de variância e as médias comparadas pelo teste de Tukey.

Adultos recém-emergidos de C. externa, originários de larvas mantidas sobre discos foliares das cultivares de algodoeiro e alimentadas com pulgões A. gossypii foram separados por sexo e cada casal transferido para gaiola cilíndrica de $P V C$ de $10 \mathrm{~cm}$ de diâmetro por $10 \mathrm{~cm}$ de altura.

O alimento e a água foram fornecidos conforme consta na descrição da técnica de criação. As observações foram realizadas diariamente, avaliando-se os parâmetros: períodos de pré-oviposição e oviposição; capacidade diária e total de oviposição e longevidade de adultos.

O delineamento utilizado foi o inteiramente casualizado com cada tratamento constituído por um casal de C. externa em seis repetições e as médias comparadas pelo teste de Tukey a 5\% de probabilidade.

\subsection{Capacidade predatória de larvas de C.externa}

Foram oferecidas diariamente 15,30 e 120 ninfas de terceiro e quarto ínstares de $A$. gossypii, respectivamente, para as larvas de primeiro, segundo e terceiro ínstares do crisopídeo. Essas presas foram liberadas sobre discos foliares de $5 \mathrm{~cm}$ de diâmetro de cada cultivar de algodoeiro, mantido em camada de ágar a $1 \%$ em placas de Petri de $12 \mathrm{~cm}$ de diâmetro. Larvas recém-eclodidas de C. externa foram individualizadas em cada uma dessas placas.

A contagem das ninfas de $A$. gossypii remanescentes foi feita sempre a cada 24 horas e o consumo determinado como a diferença diária entre o número de ninfas fornecidas e as remanescentes. Avaliramse o consumo diário e o total durante cada ínstar da fase larval de C. externa. Utilizou-se o delineamento inteiramente casualizado com três tratamentos representados pelos discos de folhas das cultivares de algodoeiro Antares, CNPA 7H e Deltapine Acala 90 em dez repetições por tratamento. Os dados foram submetidos à análise de variância e as médias comparadas pelo teste de Tukey. 


\section{RESULTADOS E DISCUSSÃO}

\subsection{Aspectos biológicos da fase jovem de C.externa}

A densidade de tricomas das cultivares de algodoeiro não influenciou a duração e a viabilidade das fases de desenvolvimento de C. externa (Quadros 1 e 2). De acordo com Bergman e Tingey (1979), os tricomas não glandulares apenas interferem no espaço requerido pelo inimigo natural para sua locomoção na planta, não afetando os inimigos naturais como os tricomas glandulares. O primeiro ínstar durou em média 3,4 dias, enquanto o segundo e terceiro ínstares duraram, 2,9 e 3,7 dias respectivamente. As durações médias das fases de larva, pré-pupa e pupa, 10,1;3,1 e 7,0 dias, respectivamente, coincidiram com aquelas verificadas por RiBEIRO (1988), que estudou também o desenvolvimento de C. externa alimentada com $A$. gossypii. O período entre a eclosão da larva e a emergência do adulto (20,2 dias) foi próximo daquele $(19,9$ dias) verificado por LiU e CHEN (2001) para Chrysoperla carnea (Stephens) alimentada com o pulgão A. gossypii. A viabilidade nos três ínstares de $C$. externa foi maior que $90,0 \%$ (Quadro 1), resultado coincidente com o de Ribeiro (1990), considerando a mesma espécie de crisopídeo e presa, e similar aos valores obtidos por CHen e Liu (2001), para C. rufilabris alimentada com A. gossypii. O percentual de sobrevivência média da fase de pré-pupa foi de 100,0\%, enquanto o de pupa, 90,3\% (Quadro 2). Embora as larvas de C. externa alimentadas de $A$. gossypii sobre folhas pilosas da cultivar de algodoeiro, Deltapine Acala 90, tenham apresentado viabilidade na fase pupal de $80,0 \%$, valor aparentemente menor que nos demais genótipos, não houve diferença significativa entre as médias (Quadro 2).

Durante o período de larva a adulto, o percentual de sobrevivência foi em média de 83,4, 96,0 e $76,0 \%$ quando larvas de C. externa foram mantidas sobre discos de folhas das cultivares Antares, CNPA 7H e Deltapine Acala 90, respectivamente pouco pilosa, hirsuta e pilosa (Quadro 2). CHEN e LiU (2001) relataram $100,0 \%$ de sobrevivência para larvas de $C$. rufilabris mantidas em discos de folha de algodoeiro, cultivar Stoneville 454 e alimentadas com A. gossypii.

Durante o segundo ínstar, larvas de C. externa alimentadas com $A$. gossypii sobre discos de folhas da cultivar CNPA 7H, de característica hirsuta, apresentaram menor massa $(1,3 \mathrm{mg})$ quando comparadas àquelas mantidas em discos de folha da cultivar Antares (pouco pilosa), não diferindo, no entanto, significativamente daquelas mantidas sobre folhas de ‘Deltapine Acala 90' de característica pilosa (Figura 1).
A massa de larvas de terceiro ínstar não variou entre os tratamentos, resultado coincidente ao de TREACY et al. (1987), no qual relataram que larvas de terceiro ínstar de C. rufilabris, por serem de tamanho maior que as dos demais ínstares, não sofreram influência das cultivares de algodoeiro com alta densidade de tricomas.

\subsection{Aspectos biológicos da fase adulta de C. externa}

Não se verificou diferença significativa para o período de pré-oviposição de C. externa originada de larvas alimentadas com $A$. gossypii sobre discos de folhas de cultivares de algodoeiro com diferentes densidades de tricomas (Quadro 3). Esse período durou em média 4,4 a 6,0 dias, valores superiores àqueles observados por Ribeiro et al. (1991) e CARVALHO et al. (1998) para adultos de C. externa alimentados durante a fase larval com ovos de $A$. argillacea. No entanto, aqueles valores são próximos ao de MANNAN et al. (1997) para adultos de C. carnea originários de larvas alimentadas com $A$. gossypii.

Fêmeas de C. externa alimentadas durante a fase larval com A. gossypii sobre discos de folhas da cultivar Antares (pouco pilosa) apresentaram maior período de oviposição (61,7 dias) em comparação àquelas fêmeas que permaneceram durante a fase imatura sobre discos foliares de 'CNPA 7H' (hirsuta) e 'Deltapine Acala 90' (pilosa), respectivamente, 46,0 e 42,2 dias (Quadro 3).

Embora o período de oviposição de C. externa tenha sofrido influência das cultivares de algodoeiro, nas quais essa espécie foi criada durante a fase larval, verificou-se que a capacidade diária e total de ovos por fêmea do predador não sofreu efeito significativo das cultivares. Fêmeas de C. externa ovipositaram diariamente 17,7 a 19,1 ovos, valores próximos àqueles determinados por Figueira et al. (2002) para C. externa originária de larvas alimentadas com Schizaphis graminum (Rondani) criado em genótipos de sorgo. No presente trabalho, a capacidade total de oviposição foi, no mínimo, de 718,5 e máximo de 951,2 ovos.

Em outras pesquisas, no entanto, tem-se verificado a ocorrência de efeitos dos tricomas sobre a taxa de oviposição. SENGONCA e GERLACH (1984) observaram que os tricomas do feijoeiro, Phaseolus vulgaris, afetaram adversamente a taxa de oviposição do predador Scolothrips longicornis Priesner. Já HeInZ e ZaLOM (1996) observaram que fêmeas do coccinelídeo D. pusillus, alimentando-se de ninfas de mosca-branca em cultivares glabras de tomate, apresentaram período de fecundidade cinco vezes maior do que aquelas mantidas em cultivar pubescente. 


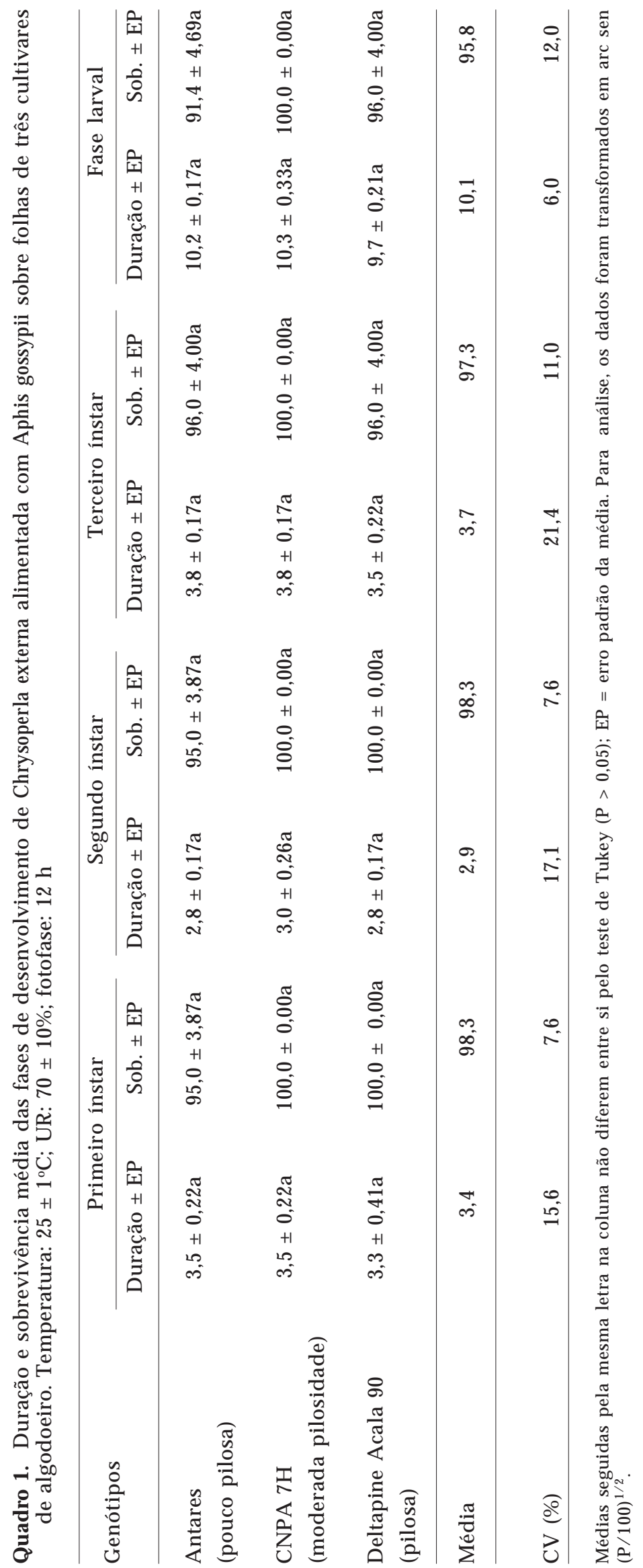




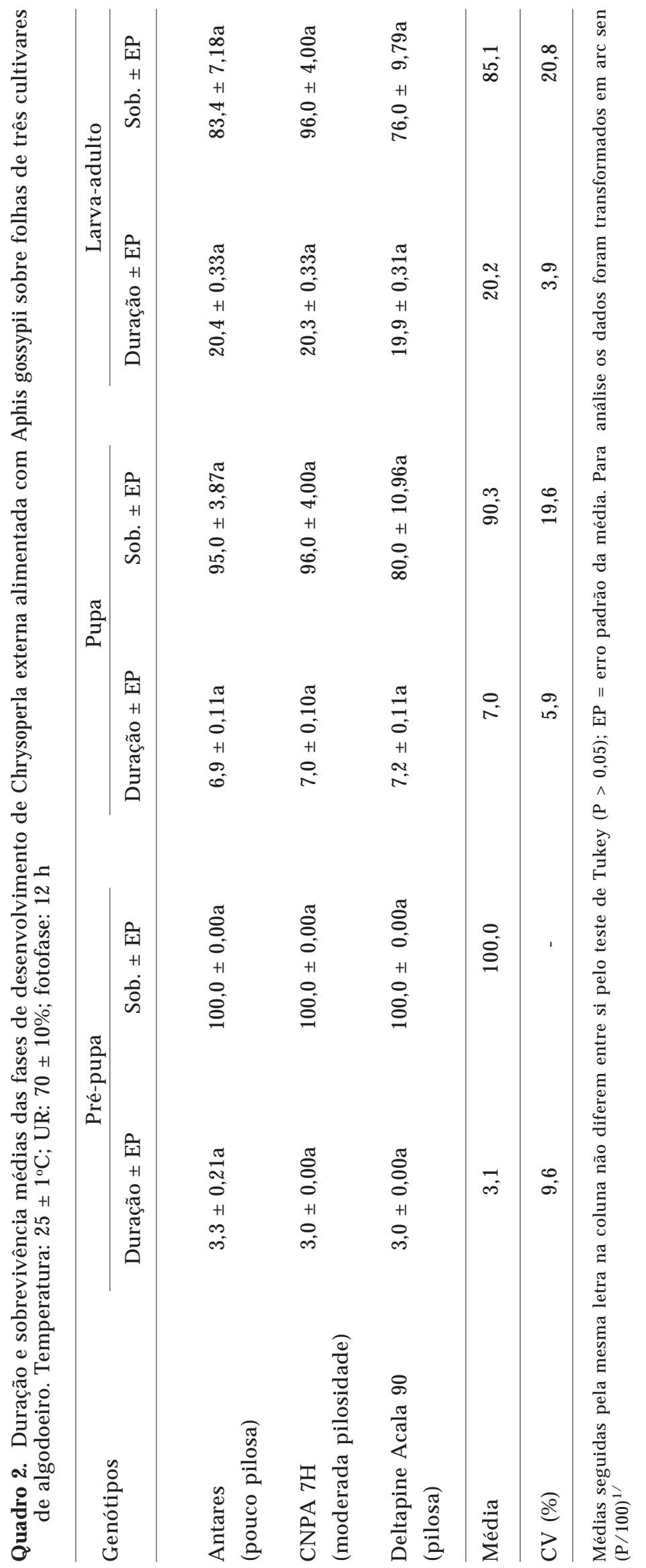


As cultivares de algodoeiro, nas quais foram mantidas as larvas de $C$. externa não influenciaram significativamente a longevidade dos machos desse predador, mas afetaram a longevidade das fêmeas (Quadro 4). Os machos apresentaram longevidade maior, variando de 61,0 a 83,2 dias, enquanto para fêmeas esse parâmetro foi de 39,7 a 76,3 dias. Fêmeas alimentadas com $A$. gossypii durante a fase larval e mantidas sobre folhas da cultivar Antares de característica pouco pilosa, viveram em média 76,3 dias, período significativamente maior que os constatados para fêmeas mantidas durante a fase jovem alimentando-se de A. gossypii sobre folhas de 'CNPA 7H' e 'Deltapine Acala 90', respectivamente, hirsuta e de alta pilosidade.

Considerando-se os resultados, constata-se que não houve efeito prejudicial dos tricomas das cultivares de algodoeiro sobre o desenvolvimento do predador.

\subsection{Capacidade predatória}

Larvas de primeiro ínstar de C. externa consumiram diariamente em média, 5,1 a 6,3 e um total de 17,4 a 21,2 pulgões (Quadro 5). Durante o segundo ínstar, o número médio diário e total de pulgões A. gossypii consumidos por larvas de C. externa foi influenciado pelas cultivares de algodoeiro sobre as quais foram mantidas esse predador. As caraterísticas pilosidade e comprimento de tricomas podem influenciar a capacidade do inimigo natural em descobrir e alimentar-se de sua presa em diferentes plantas hospedeiras (HARE, 1992).

Presumia-se que as larvas de segundo instar, mantidas sobre folhas de 'CNPA $7 \mathrm{H}^{\prime}$ capturasse e consumisse menor número de pulgões, em comparação às larvas mantidas sobre discos de folhas de 'Antares', de característica pouco pilosa, já que aquelas apresentaram menor massa (Figura 1).

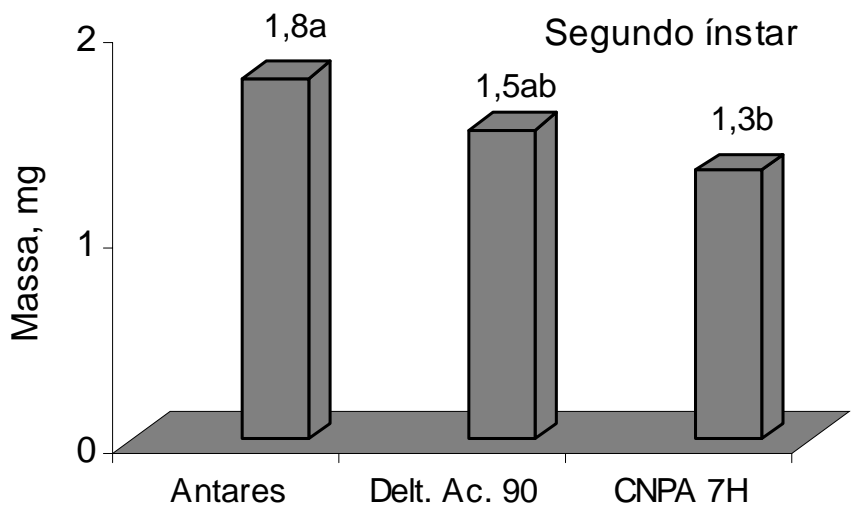

Terceiro ínstar

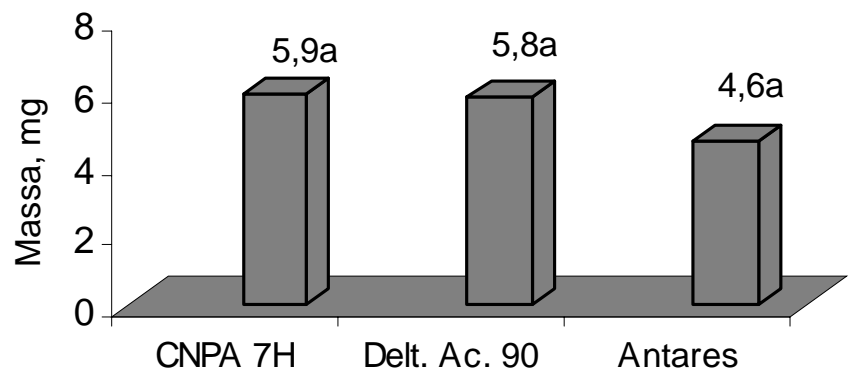

Figura 1. Massa média (mg) de larvas de segundo e terceiro ínstares de Chrysoperla externa alimentada com Aphis gossypii sobre folhas de três cultivares de algodoeiro. Temperatura: $25 \pm 1^{\circ} \mathrm{C}$; UR: $70 \pm 10 \%$; fotofase: $12 \mathrm{~h}$. 


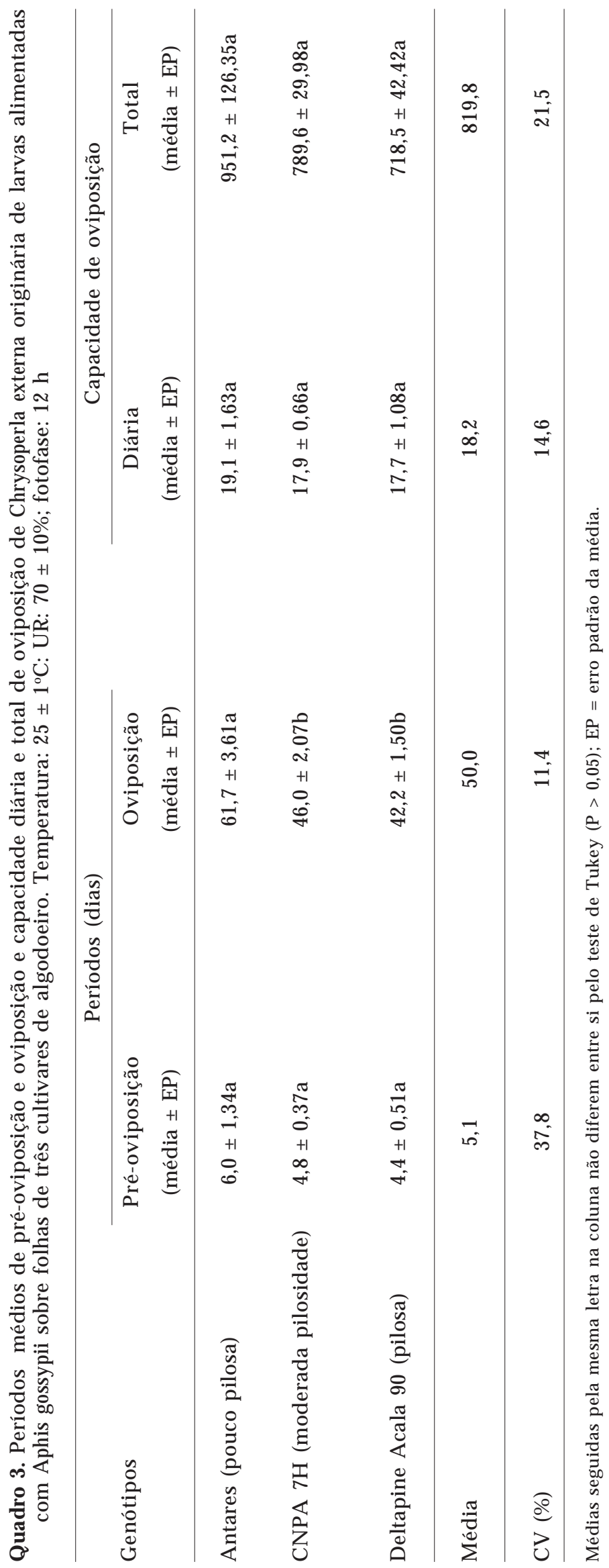


Quadro 4. Longevidade média de Chrysoperla externa originada de larvas alimentadas com Aphis gossypii sobre folhas de três cultivares de algodoeiro. Temperatura: $25 \pm 1^{\circ} \mathrm{C}$; UR: $70 \pm 10 \%$; fotofase: $12 \mathrm{~h}$

\begin{tabular}{lcr}
\hline \multirow{2}{*}{ Cultivares } & & Longevidade \\
\cline { 2 - 3 } & Macho (média \pm EP) & Fêmea (média \pm EP) \\
\hline Antares (pouco pilosa) & $83,2 \pm 6,49 \mathrm{a}$ & $76,3 \pm 3,70 \mathrm{a}$ \\
CNPA 7H (moderada pilosidade) & $61,3 \pm 3,66 \mathrm{a}$ & $39,7 \pm 3,47 \mathrm{~b}$ \\
Deltapine Acala 90 (pilosa) & $61,0 \pm 8,22 \mathrm{a}$ & $53,7 \pm 6,40 \mathrm{~b}$ \\
\hline Média & 68,5 & 56,6 \\
\hline CV $(\%)$ & 20,9 & 18,6 \\
\hline
\end{tabular}

Médias seguidas pela mesma letra na coluna não diferem entre si pelo teste de Tukey $(\mathrm{P}>0,05)$; EP = erro padrão da média.

No entanto, as larvas nesse estádio consumiram maior número de pulgões em relação àquelas mantidas em disco de folha pilosa, cultivar Deltapine Acala 90, não diferindo significativamente do consumo das larvas de segundo ínstar mantidas em discos foliares de 'Antares' (Quadro 5).

$\mathrm{O}$ fato de a larva ter apresentado menos massa no material hirsuto, onde ocorreu maior consumo, provavelmente se deva à necessidade de maior locomoção para localizar as presas, o que deve ter provocado maior gasto de energia. Segundo $\mathrm{SHAH}$ (1982), plantas com níveis moderados de pubescência podem melhorar a eficiência de alguns inimigos naturais, intensificando sua taxa de circulação enquanto caminha, aumentando a probabilidade de encontro com a presa.

Nesse caso, não ocorreu uma associação linear entre a taxa de predação e a densidade de tricomas, confirmando os resultados de Mohite e Uthamassamy (1998), que verificaram menor taxa de predação de ovos de $H$. zea por larvas de C. carnea em folhas de algodoeiro com menor número de tricomas em comparação a cultivares de folhas mais pilosas.

O resultado deste trabalho contrasta com o de TREACY et al. (1985), que verificaram, em casa de vegetação, menor número de ovos de $H$. zea predados por larvas de C. externa em plantas de algodão com alta densidade de tricomas, em relação a larvas mantidas em plantas de características de hirsuta e glabra. Já o consumo diário e total de pulgões $A$. gossypii por larvas de C. externa, durante o terceiro instar, não foi influenciado pelas cultivares de algodoeiro, concordando com TREACY et al. (1987). Segundo esses autores, larvas de crisopídeo de terceiro ínstar são menos afetadas pelos tricomas do algodoeiro, devido ao maior tamanho em relação às de primeiro e segundo ínstares. Essa observação é importante, pois foi durante o terceiro ínstar que a larva de C. externa consumiu o maior percentual de pulgões, $83,4 \% ; 84,2 \%$ e $84,5 \%$, para larvas mantidas, respectivamente, sobre folhas das cultivares CNPA 7H, Antares e Deltapine Acala 90.

Durante a fase larval, C. externa apresentou o mesmo comportamento de predação ocorrido durante o segundo ínstar (Quadro 5). O número de pulgões consumidos por larvas do crisopídeo durante esse período, quando mantidas sobre folhas pouco pilosas da cultivar Antares e sobre folhas hirsutas de CNPA $7 \mathrm{H}$, não foram significativamente diferentes; no entanto, a predação nessa última condição foi maior que a das larvas mantidas sobre folhas pilosas da cultivar Deltapine Acala 90.

Esse resultado contrasta com o de SHAH (1982), que observou um incremento na taxa de predação de Adalia bipunctata L., devido aos tricomas presentes no repolho chinês, já que as larvas desse predador caminhavam mudando de direção freqüentemente, resultando em maiores encontros com o pulgão-presa. De acordo com Treacy et al. (1987), o impacto da pilosidade da planta hospedeira sobre o inimigo natural varia com a cultivar e espécie de presa da qual o predador está se alimentando.

Em condições de laboratório, os tricomas das cultivares testadas não influenciaram adversamente o tempo de desenvolvimento, sobrevivência, oviposição e a taxa de predação de C. externa. Entretanto, sugerem-se estudos similares e complementares em casa de vegetação e campo, para a implementação desses resultados em programas visando ao manejo integrado do pulgão do algodoeiro. 


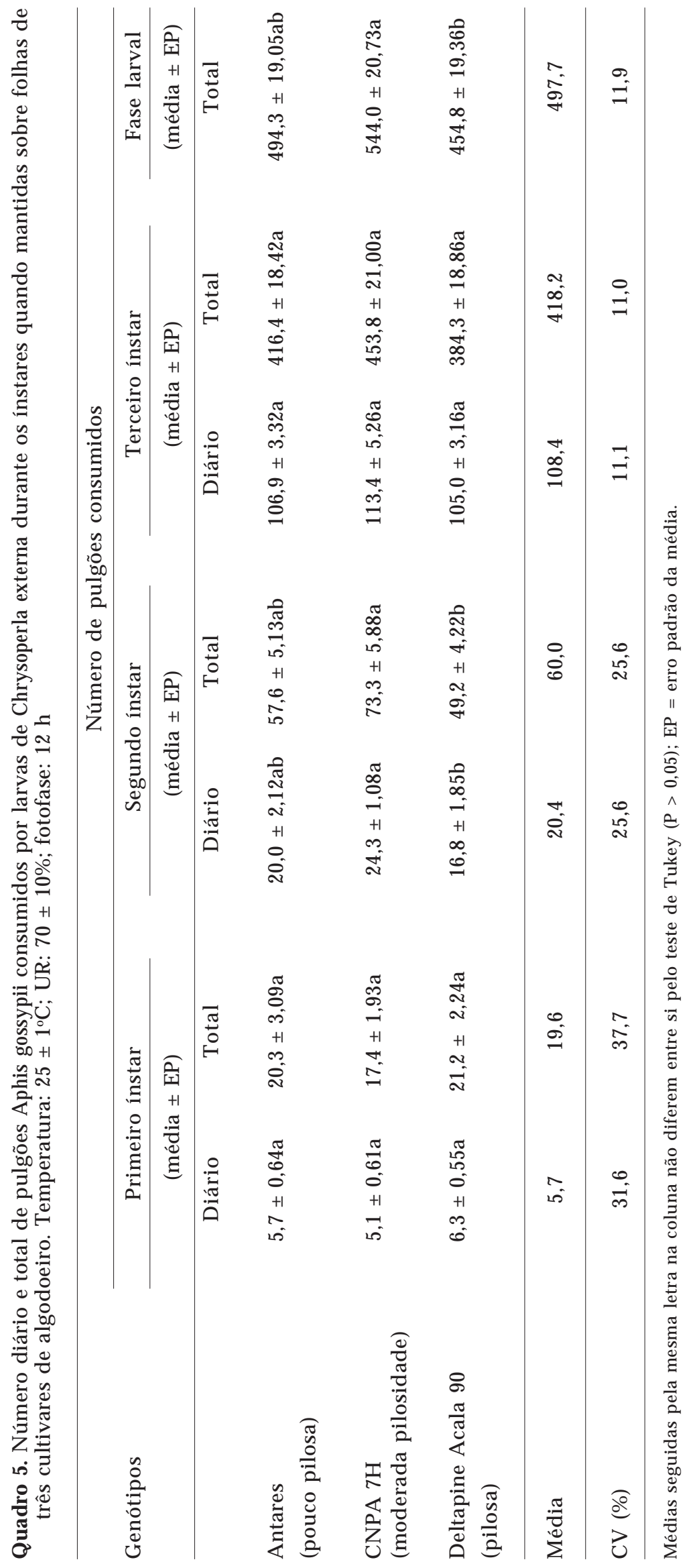




\section{CONCLUSÃO}

As cultivares de algodoeiro avaliadas (Antares, CNPA 7H e Deltapine Acala 90) demonstraram compatibilidade com o predador C. externa, o que indica a possibilidade de integração de cultivares resistentes com diferentes níveis de densidade de tricomas com esse crisopídeo para controle do pulgão A. gossypii.

\section{AGRADECIMENTOS}

À FAPESP pela concessão de bolsa de pósdoutorado ao primeiro autor e pelo suporte financeiro à pesquisa.

\section{REFERÊNCIAS BIBLIOGRÁFICAS}

ARANTES, N.E.; PENNA, J.C.V.; SILVA, C.M. Algodão: principais pragas da cultura e seu manejo. In: APSEMG (Ed.). Guia Técnico Algodão e Soja. Belo Horizonte, 1998, p.34-71.

BARBOUR, J.D., FARRAR JR, R. R.; KENNEDY, G. G. Populations of predaceous natural enemies developing on insect-resistant and susceptible tomato in North Carolina. Biological Control, Orlando, v.9, n.3, p.173-84, 1997.

BERGMAN, J.M.; TINGEY, W.M. Aspects of interactions between plant genotypes and biological control . Bulletin of the Entomological Society of America, Lanham, v.25, n.4, p.275279, 1979.

BOTRELL, D. G.; BARBOSA, P.; GOULD, F. Manipulating natural enemies by plant variety selection and modification: a realistic strategy? Annual Review of Entomology, Palo Alto, v.43, p.347-367, 1998.

CARVALHO, C.F.; SOUZA, B.; SANTOS, T.M. Predation capacity and reproduction potential of Chrysoperla externa (Hagen) (Neuroptera: Chrysopidae) fed on Alabama argillacea (Hübner) eggs. Acta Zoologica Fennica, Helsinki, v.209, p.83-86, 1998.

CARVALHO, P. P. Pragas principais e seu controle. In: (Ed.). Manual do Algodoeiro. Lisboa: Instituto de Investigação Científica Tropical, 1996. p.89-106.

CHEN, T. Y.; LIU, T. X. Relative consumption of three aphid species by the lacewing, Chrysoperla rufilabris, and effects on its development and survival. Biocontrol, Dordrecht, v.46, n.4, p.481-491, 2001.

FIGUEIRA, L. K.; LARA, F. M.; CRUZ, I. Efeito de genótipos de sorgo sobre o predador Chrysoperla externa (Hagen) (Neuroptera: Chrysopidae) alimentado com Schizaphis graminum (Rondani) (Hemiptera: Aphididae). Neotropical Entomology, Londrina, v.31, n.1, p.133-139, 2002.
HARE, J. D. Effects of plant variation on herbivore-natural enemy interactions. In: FRITZ, R.S. SIMMS, E.L. (Eds.). Plant resistance to herbivorous and pathogens: ecology, evolution and genetics. Chicago: The University of Chicago Press, 1992. p.283-284.

HARRIS, F. A.; CALHOUN, D. S.; FURR, R. JR. Cotton varietal resistance to cotton aphid. In: BELTWIDE COTTON CONFERENCE, 1994, San Diego. Proceedings... p.1007-1008.

HEINZ, K. M.; PARRELLA, M. P. Poinsettia (Euphorbia pulcherrima Wild Ex Koltz) cultivar mediated differences in performance of five natural enemies of Bemisia argentifolii Bellows and Perring, n. sp. (Homoptera: Aleyrodidae). Biological Control, Orlando, v.4, p.305-308, 1994.

HEINZ, K. M.; ZALOM, F. G. Performance of the predator Delphastus pusillus on Bemisia tabaci resistant and susceptible tomato lines. Entomologia Experimentalis et Aplicatta, Dordrecht, v.81, p.345-352, 1996.

KABISSA, J. C. B.; KAYUMBO, H. Y.; YARRO, J. G. Seasonal abundance of chrysopids (Neuroptera: Chrysopidae) preying Helicoverpa armigera (Hubner) (Lepidoptera: Noctuidae) and Aphis gossypii (Glover) (Homoptera: Aphididae) on cotton in eastern Tanzania. Crop Protection, Oxford, v.15, n.1, p.5-8, 1996.

LIU, T. X.; CHEN, T. Y Effects of three aphid species (Homoptera: Aphididae) on development, survival and predation of Chrysoperla carnea (Neuroptera: Chrysopidae). Applied Entomology and Zoology, Tokyo, v.36, n.3, p.361-366, 2001.

MAEDA, L. T. Efeito de tricomas de cultivares de algodoeiro sobre a biologia e capacidade predatória de larvas de Chrysoperla externa (Hagen) (Neuroptera: Chrysopidae) alimentada com ovos de Alabama argillacea (Hübner) (Lepidoptera: Noctuidae). 2002. 53f. Trabalho de graduação - Faculdade de Ciências Agrárias e Veterinárias-UNESP, Jaboticabal.

MANNAN, V. D.; VARMA, G. C.; BRAR, K. S. Biology of Chrysoperla carnea (Stephens) on Aphis gossypii and Myzus persicae (Sulzer). Journal of Insect Science, Punjab, v.10, p.143$145,1997$.

MATTHEWS, G. A. Early season pests. In: Matthews, G. A. (Ed.) Cotton insects pests and their management. Berkshire: Longman Cientific \& Technical, 1989. p.16-26.

MOHITE, P. B.; UTHAMASAMY, S. Host-plant resistance and natural enemies interaction in the management of Helicoverpa zea (Hübner) on cotton. Indian Journal of Agricultural Research, Haryana, v.32, p.28-30, 1998.

NAVEED, M.; ATTIQUE, M R.; RAFIQUE, M. Role of leaf hairs of different cotton varieties on the population development of cotton aphid (Aphis gossypii Glover). Pakistan Journal of Zoology, Lahore, v.27, n.3, p.277-278, 1995.

POWELL, J.E.; LAMBERT, L. Soybean genotype effects on bigeyed bug feeding on corn earworm in the laboratory. Crop Science, Madison, v. 33, n.3, p.556-559, 1993. 
RIBEIRO, M.J. Biologia de Chrysoperla externa (Hagen, 1861) (Neuroptera: Chrsyopidae) alimentada com diferentes dietas. Lavras, 1988. 131p. Dissertação. (Mestrado em Agronomia) - Universidade Federal de Lavras.

RIBEIRO, M.J. Biology of Chrysoperla externa (Hagen, 1861) (Neuroptera: Chrsyopidae) fed with different diets. Neuroptera International, Nice, v.6, p.85-86, 1990.

RIBEIRO, M.J.; CARVALHO, C.F.; MATIOLI, J.C. Influência da alimentação larval sobre a biologia de adultos de Chrysoperla externa (Hagen, 1861) (Neuroptera: Chrysopidae). Ciência e Prática, Lavras, v.15, n.4, p.349-354, 1991.

SANTOS, W. J. Pragas do Algodoeiro. In: Mato Grosso Liderança e Competitividade. Rondonópolis: Fundação MT/EMBRAPA, 1999. p.113-149. (Boletim, 3).

SENGONCA, C.; GERLACH, S. Einfluss der blattoberflache auf die wirksamkeit des rauberischen thrips, Scolothrips longicornis (Thysan.: Thrypidae). Entomophaga, Paris, v.29, n.1, p. 55-61, 1984.

SHAH, M. A. Influence of plant surfaces on the searching behaviour of Coccinellid larvae. Entomologia Experimentalis et Aplicatta, Dordrecht, v.31, p.377-802, 1982.
TREACY, M. F.; ZUMMO, G. R.; BENEDICT, J. H. Interactions of host-plant resistance in cotton with predators and parasites. Agriculture, Ecosystems and Environment, Amsterdam, v.13, p.151-7, 1985.

TREACY, M.F.; BENEDICT, J.H.; LOPEZ, J.D.; MORRISON, R.K. Functional response of a predator (Neuroptera: Chrysopidae) to bollworm (Lepidoptera: Noctuidae) eggs on smoothleaf, hirsute, and pilose cottons. Journal of Economic Entomology, Lanham, v.80, n.2, p.376-9, 1987.

WEATHERSBEE III, A.A., HARDEE, D.D. Abundance of cotton aphids (Homoptera: Aphididae) and associated biological control agents on six cotton cultivars. Journal of Economic Entomology, Lanham, v.87, n.1, p.258-265, 1994.

WEATHERSBEE III, A.A., HARDEE, D.D., MEREDITH Jr., W.R. Differences in yield response to cotton aphids (Homoptera: Aphididae) between smooth leaf and hairy-leaf isogenic cotton lines. Journal of Economic Entomology, Lanham, v.88, n.3, p.74954, 1995. 